\title{
Analysis of the Influences of Piston Crankshaft Offset on Piston Secondary Movements
}

\author{
Yan Hongwei*, Yang Jin and Zhang Baocheng
}

School of Mechanical and Power Engineering, North University of China, Taiyuan, Shanxi, 030051, P.R. China

\begin{abstract}
This paper takes dynamics analysis on the piston and the dynamic lubrication theory on the skirt and the ring of piston as the basis. Using AVL Glide software, through the establishment of the analysis model of the piston secondary movements, this study focuses on the effects of the crankshaft bias on piston secondary movements' characteristics. This paper takes 5 different offsets, by comparing the piston lateral displacement, transverse movement speed, transverse acceleration, swinging angle, swing angular velocity and angular acceleration, finds out the relationships between crank offset value and the piston "slap", piston impact energy and piston skirt friction loss, thus, provides the basis for the design of internal combustion engines.
\end{abstract}

Keywords: Crank offset, piston, piston impact energy, secondary movement.

\section{INTRODUCTION}

The piston secondary movements are some small movements exist in the processes of the reciprocating work of internal combustion engines. They specifically refer to, under the pressure of the gas deflagration, inertia force, the connecting rod force, friction force and oil film, except for linear motion (first order motion), there still exists lateral movements and the swing motions around the piston pin [1]. The piston secondary movements have effects on the performances, working reliability and the service life of the internal combustion engines, and other aspects of influences can also not be ignored. The concrete manifestations are: the influence of cylinder liner piston strokes, thereby affecting the body vibration and the piston knock noise; direct effect of cylinder liner scuffing, cavitations and the piston "slap" noise; impact the wear of piston ring, and then change the performance of piston ring sealing and heat transfer [2]. In addition, piston secondary movements are the basis of the study of behavior of piston modules' friction loss, and for internal combustion engines, they have important influences on the friction loss of piston skirt [3]. Therefore, studying on the piston secondary movements' characteristics has great influence on the various aspects listed above [4].

In this paper, based on the researches in the domestic and foreign on the secondary motions of the piston, the research focuses on of the effects on the crank offset of piston, providing a reference for the design of the piston and the other module parts [5].

\section{SMIMULATION MODEL}

\subsection{Data Preparation}

The analysis of piston secondary movements relates to the thermal deformation calculation of piston and cylinder liner, piston stiffness matrices' calculation, the confirmation of the mass of piston group, confirmation of inertia and data preparation [6]. Other needed data mainly includes parameters of the piston and cylinder liner piston structure size, the mass of all parts of the group and inertia and crankshaft connecting rod size [7]. Parameters like the center position of mass, moment of inertia can be obtained by means of CAD modeling, as for the other parameters can be obtained by the design drawings. Other technical information and specific data can be seen in Table 1 [8].

\subsection{The Analysis Model}

Based on the previous theoretical analysis, combined with previous data preparation work, the piston dynamics model can be established by using AVL software Glide module. The purpose of this paper is the analysis of piston kinematics, rather than the piston gas channeling and other issues, so we can use simple equivalent piston ring group describes the piston rings [9]. Schematic diagram is shown in Fig. (1).

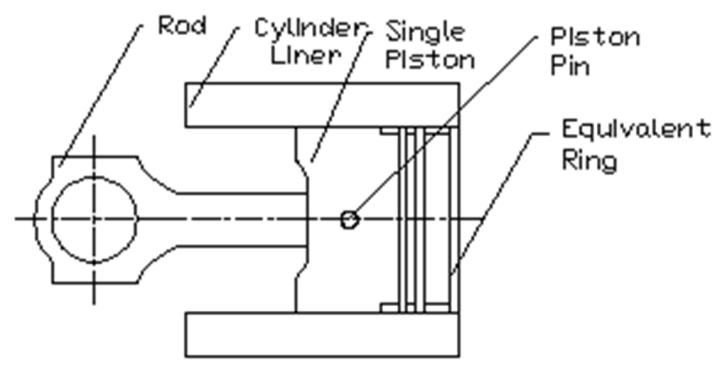

Fig. (1). Sketch map of piston motion model.

\section{EFFECTS OF CRANKSHAFT OFFSET ON PISTON SECONDARY MOTIONS}

Crank offset techniques have been applied by a lot of advanced engine manufacturers to the mass of actual engine productions, in order to reduce piston friction, improve the service life of the engine components [10]. According to the literature, the relative eccentricity (ratio of eccentricity E and 
Table 1. Main data for analysis.

\begin{tabular}{|c|c|c|c|c|}
\hline \multirow{2}{*}{ The mass of the piston ring $(\mathrm{kg})$} & No. 1 & 0.0393 & \multirow{2}{*}{$\begin{array}{l}\text { Cylinder liner inclination angle } \\
\qquad\left(^{\circ}\right)\end{array}$} & \multirow{2}{*}{0} \\
\hline & No. 3 & 0.0397 & & \\
\hline \multirow{3}{*}{ The distance from ring center to pin center $(\mathrm{mm})$} & No. 1 & 69.9 & \multirow{3}{*}{ The length of the connecting rod (mm) } & \multirow{3}{*}{266.1} \\
\hline & No. 2 & 57.7 & & \\
\hline & No. 3 & 49.8 & & \\
\hline Moment of inertia $\left(\mathrm{kg} \cdot \mathrm{mm}^{2}\right)$ & \multicolumn{2}{|c|}{5807.4} & The quality of connecting rod $(\mathrm{kg})$ & 2.947 \\
\hline The quality of piston pin $(\mathrm{kg})$ & \multicolumn{2}{|c|}{1.345} & The distance from piston pin center to the top of piston $(\mathrm{mm})$ & 86.8 \\
\hline
\end{tabular}

(1-2)

\begin{tabular}{|c|c|c|c|}
\hline The quality of piston $(\mathrm{kg})$ & 2.398 & Moment of inertia around quality center $\left(\mathrm{kg} \cdot \mathrm{mm}^{2}\right)$ & 33572.8 \\
\hline The connecting rod big end diameter (mm) & 91.0 & The connecting rod small end diameter $(\mathrm{mm})$ & 55.0 \\
\hline Cylinder liner length $(\mathrm{mm})$ & 278.8 & Distance from top of cylinder liner to center of crank ( $\mathrm{mm})$ & 426.5 \\
\hline Compression height (mm) & 73.0 & The clearance of cylinder (mm) & 0.21 \\
\hline \multirow{2}{*}{ The number of stroke } & \multirow{2}{*}{4} & \multicolumn{2}{|l|}{ Piston meshing and node labels } \\
\hline & & Pistoner & \\
\hline Piston diameter $(\mathrm{mm})$ & 131.8 & & \\
\hline Piston height (mm) & 133.8 & & \\
\hline The crank radius $(\mathrm{mm})$ & 72.5 & & \\
\hline
\end{tabular}

crank radius $R$ ) value is generally in the range 0.05 to 0.25 [11]. So take 5 groups relative eccentricity to analyze the influence of crankshaft offset on piston secondary motions, respectively $-0.2,-0.1,0,0.1,0.2$, eccentricity of the corresponding E were $-14.5 \mathrm{~mm},-7.25 \mathrm{~mm}, 0 \mathrm{~mm}, 7.25 \mathrm{~mm}$, $14.5 \mathrm{~mm}$. Among them, the positive bias for positive eccentric crankshaft piston means that the crank is bias to the main thrust face side [12].

\subsection{Effects of Crankshaft Bias on Piston Transverse Movements}

Figs. (2-7) is the piston transverse movement comparison chart of piston secondary movements under different crank offsets. Figs. (2-4) represents the influence of crankshaft bias on piston transverse movements. We can see from Fig. (2), when the crankshaft is positive biased, the lateral displacement of the piston maximum at the main thrust side shows a trend of decrease, and shows a trend of increase at the secondary side thrust, furthermore, the bias is bigger, the effect is more obvious; while the negative bias effect of crankshaft has a opposite effect [13].
We can see from Fig. (3), the crankshaft offset also has certain influences on piston transverse velocity, through the crank offset can reduce the piston transverse velocity maximum, but in addition to this case, offset $-14.5 \mathrm{~mm}$, can be $25 \%$ lower than the zero biased, other crank offsets' maximums have limited effects to reduce the piston transverse movement speed value [14].

And we can see from Fig. (4), both positive and negative biased crankshafts cause the piston transverse acceleration maximum value increasing. But, under the negative bias, the acceleration maximum value increases with the increase of absolute offset; while the positive bias, the maximum acceleration value reduces with the increase of absolute bias [15].

Figs. (5-7) indicates the influence of piston crankshaft offset on piston swing. In the end of stroke and power stroke compression stages, with the increase of offset, clockwise swing angle absolute value increases, anticlockwise swing angle decreases.

Therefore, the use of the larger positive bias of crankshaft is in favor of the control of piston secondary motions. 


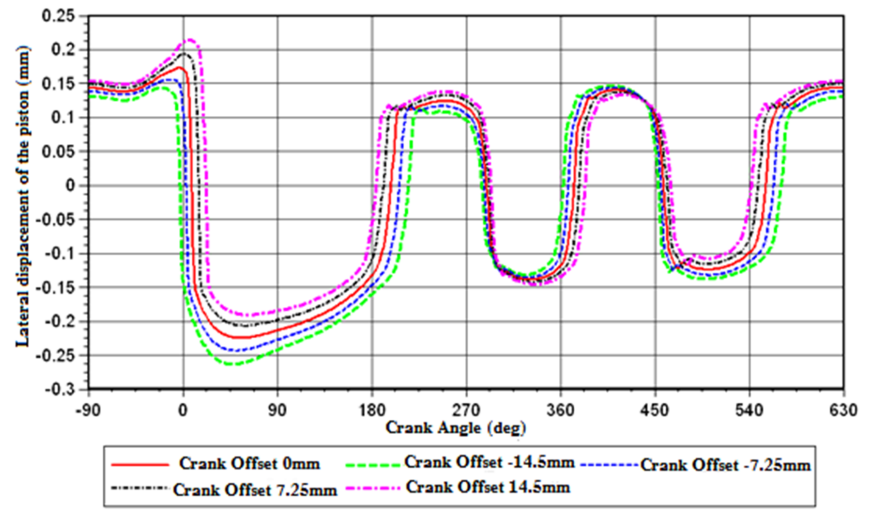

Fig. (2). Piston horizontal displacement comparison chart under different crank offset.

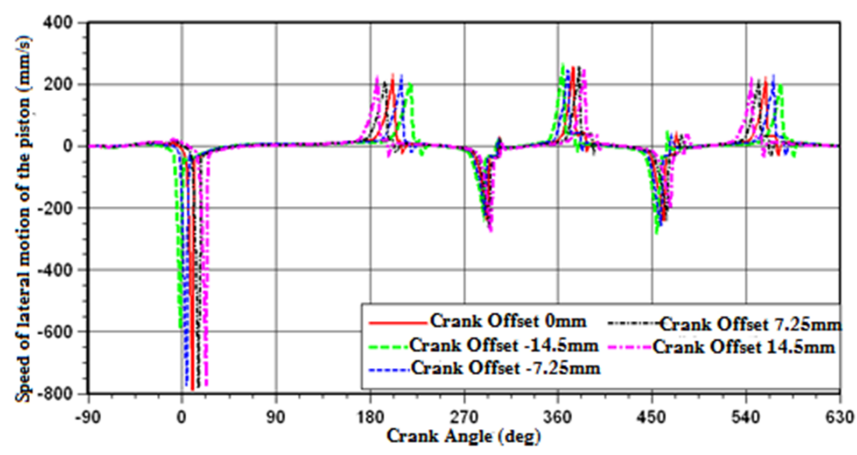

Fig. (3). Piston horizontal velocity comparison chart under different crank offset.

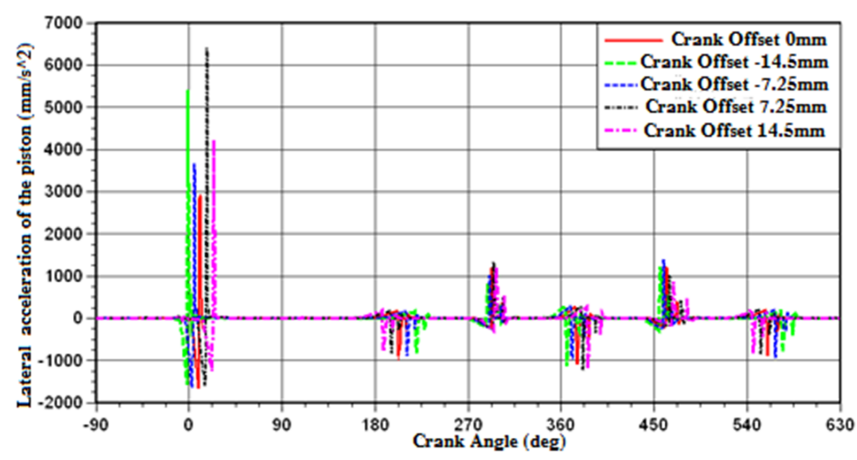

Fig. (4). Piston horizontal acceleration comparison chart under different crank offset.

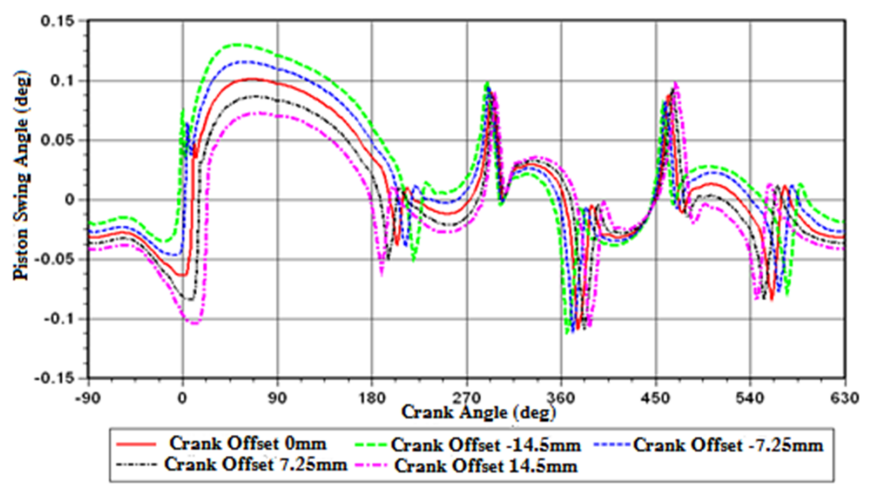

Fig. (5). Piston swing angle comparison chart under different crank offset.

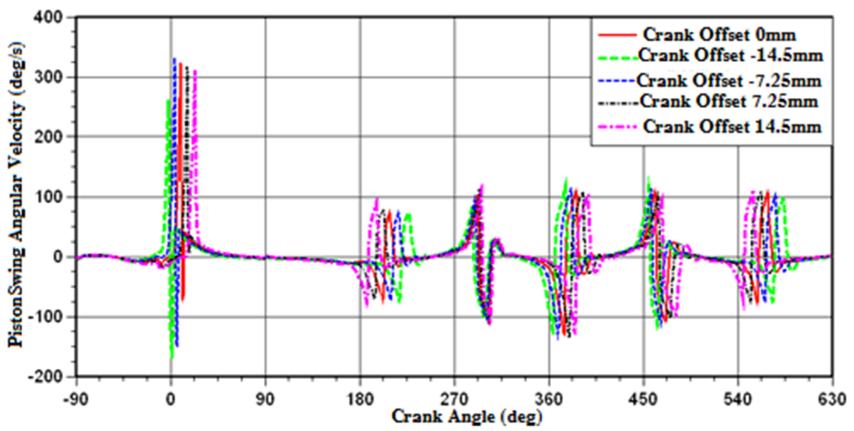

Fig. (6). Piston swing angle velocity comparison chart under different crank offset.

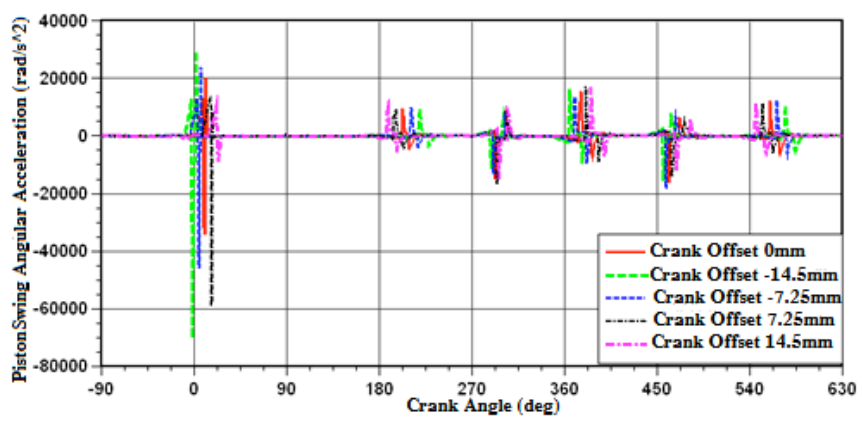

Fig. (7). Piston swing angle acceleration comparison chart under different crank offsets.

Crankshaft offset also has effects on piston swinging and transverse movement commutation time [16]. In the power stroke stage, a negative bias makes the commutation time of transverse and swinging movement ahead of time, both the lead time is consistent, and it increases with the increase of absolute crankshaft offset; and a positive bias lead to both delay, delay time of the two is roughly consistent, and it increases with the increase of the crankshaft offset. Therefore, the crankshaft offset has little effect on "attitude". In addition, we can see from Fig. (6), the crankshaft positive bias enhances stability when the piston is reversing swing in power stroke near TDC; we can see from Fig. (7), the larger crankshaft positive offset makes the piston reversing from deflagration time, reduces the acceleration maximum of piston swing in power stroke near TDC. Therefore, the larger crankshaft offset also helps to control piston "slap" [17].

\subsection{Effects of Crankshaft Bias on the Impact Energy of the Piston}

The crankshaft offset also has influence on impact energy of the piston. The contrast diagram of piston impact energy under different offsets is shown in Fig. (8).

We can see from Fig. (8), the larger crankshaft negative bias can effectively reduce the maximum of piston impact energy, if only from the perspective of reducing piston knock into account, you can choose a larger negative biased crankshaft. But in practical application, the offset mechanism of crankshaft models mostly uses the positive bias, which is based on the considerations to reduce the piston skirt friction loss. As shown in Fig. (9) is the curve of piston skirt friction 


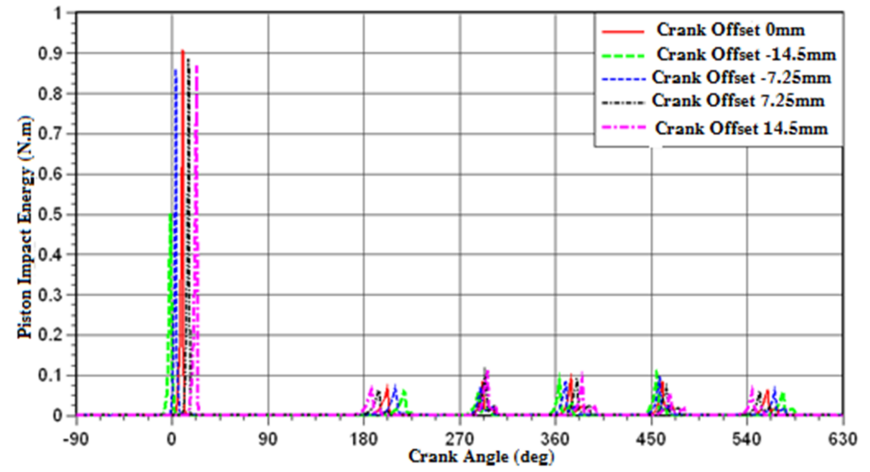

Fig. (8). Piston impact power comparison chart under different crank offset.

loss and maximum of piston impact energy under different crank offsets.

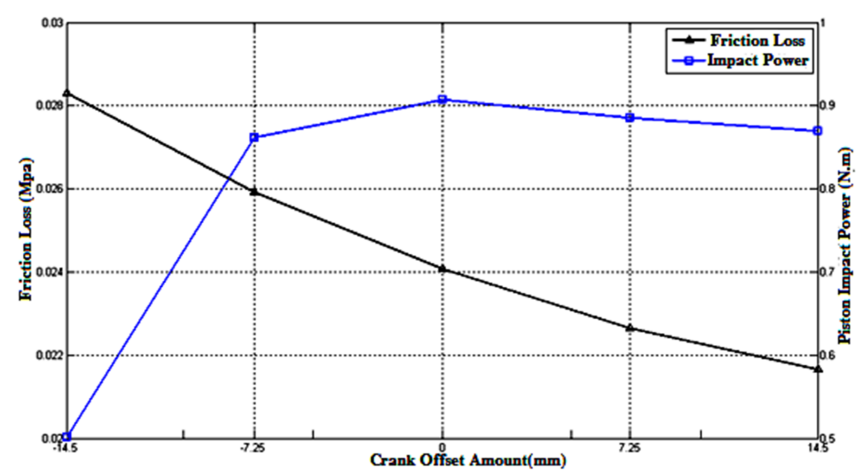

Fig. (9). The curve of piston skirt friction loss and maximum piston impact energy under different crank bias.

From the above pictures, crankshaft offset $-14.5 \mathrm{~mm}$ can significantly reduce the maximum piston impact energy, reduce about $44.7 \%$ compared to the crankshaft zero biased, but the piston skirt friction loss is greater than zero biased crank: it has increased by about $17.5 \%$. And with the increase of offsets, the piston skirt friction loss decreases. When crankshaft offset is $14.5 \mathrm{~mm}$, the piston skirt friction loss is about $10.1 \%$ less than the crankshaft zero biased, and the largest energy is reduced about $4.1 \%$ than crankshaft zero biased; when the crankshaft offset is $7.25 \mathrm{~mm}$, the piston skirt friction loss is about $6 \%$ less than the crankshaft zero biased, and the largest energy decreases about $2.3 \%$ than zero biased crankshaft. Thus, the crankshaft positive bias can both reduce the piston impact energy and the piston skirt friction loss, and both decreasing amplitude increases with the crank offset increases. Therefore, we should choose the larger positive bias in the crankshaft design process. In addition, with the increase of crankshaft offset, diesel engine size may be enlarged; in order to avoid the interferences' generation, connecting rod size may also be variable [18].

Above shows, for crankshaft offset' selection, we should consider its influence on the piston secondary motions, piston impact energy, the piston skirt friction loss and other components' dimensions. Generally, the selection of crankshaft is the larger positive offset [19].

\section{CONCLUSION}

This chapter describes the basic processes by using AVL Glide software to solve the piston secondary motions. Based on a certain type of diesel engine as the research object, we have studied the effect of piston crankshaft offset on the characteristics of piston secondary motions. The study finds: influence of crankshaft bias on the piston secondary motions is complex and has obvious influences on the piston secondary motions amplitude and commutation time. Overall, using the larger positive crankshaft bias can reduce piston secondary motions and the "piston slap" at the same time, reduces the impact energy and the piston skirt friction loss. In this example, $14.5 \mathrm{~mm}$ is the optimal crank offset.

\section{CONFLICT OF INTEREST}

The authors confirm that this article content has no conflict of interest.

\section{ACKNOWLEDGEMENTS}

The work described in this paper has been supported by the China National High Technology Research and Development Program (863 Program), under the grant (No. 2008AA06A415) Typical Coal Chemical Industry via a Serious Environmental Pollution Emergency Technology Development and Application Demonstration. The research at the same time also received a grant from the Natural Science Foundation of Shanxi Province (No. 2013011026-2), it is mainly manifested in the aspect of energy saving and environmental protection of pulverized coal the key technology of intelligent production samples. Also, the research work received support from The National Natural Science Fund of China (No. 201351275487), it mainly focuses on the research on the model and algorithm for fast computation of internal combustion engine structure under acoustic radiation and multi work conditions. The authors would like to express their gratitude for the support of this study.

\section{REFERENCES}

[1] J. Zhu, Z. Hao, and K. Zheng, "Analysis and optimization design on piston secondary motion of gasoline engine," Journal of Zhejiang University (Engineering Science), vol. 48, no. 2, pp. 334341, 2014.

[2] Y. Liu, and B. Zhang, "Effect of three factors on piston's kinetic energy of second order motion," Journal of Chinese Agricultural Mechanization, vol. 33, no. 2, pp. 110-114, 2014.

[3] B. C. Zhang, T. X. Su, and L. X. Zhang, Dynamics of Internal Combustion Engine, National Defense Industry Press, Beijing, 2009.

[4] J. L. M, and Y. W. C, "The change relation of piston cylinder rattling characteristics and wear gap," Journal of Vibration, Measurement \& Diagnosis, vol. 34, no. 5, pp. 838-843, 2014.

[5] Y. C. Li, Y. Zhang, and H. M. Yuan, "Analysis of a certain type of engine crankshaft offset," Automotive Engineer, vol. 8, pp. 44-47, Oct. 2014.

[6] F. G. Tian, and J. Sui, "Mechanical analysis of the crankshaft offset engine," Mathematical Technique and Application, vol. 11, pp. 9597, Jan. 2010. 
[7] G. Wang, R. Y. Wei, and J. X. Hu, "Dynamic simulation analysis of crank piston mechanism based on Pro/E," Journal of Soochow University Science, vol. 32, no. 4, pp. 66-70, 2012.

[8] R. Z. Xu, W. H. Zeng, and R. S. Zhang, "Research on application of crank offset technique in small general gasoline engine," Forestry Machinery and Woodworking Equipment, vol. 39, no. 10, pp. 24-25, 2011.

[9] H. Li, T. Zhou, and G. Liu, "Six cylinder piston engine dynamics modeling and numerical simulation study," Shandong Industrial Technology, vol. 11, pp. 18-19, 2014.

[10] Z. Q. Cheng, Study on the Impact of Tribological Characteristics of Internal Combustion Engine Piston Ring on the Piston Dynamics Behavior, Guangxi University, Guangxi, ON, China, 2010.

[11] F. Ji, F. Du, and S. Liu, "Numerical analysis of deformation and lubrication for piston skirt of two-stroke engine," Journal of South China University of Technology (Natural Science Edition), vol. 12, pp. 75-80, 2013

[12] W. M. Xia, K. B. Ji, and S. H. Pan, "Machine main cylinder piston rod side thrust finite element analysis of the shear hydraulic pendulum," Equipment \& Manufacturing Technology, vol. 44, no. 5, pp. 73-76, 2009.

[13] X. Li, J. M. Liu, X. Qiao, and G. Wu, "The influencing factors research of piston slap vibration from diesel," Machinery Design \& Manufacture, vol. 5, pp. 197-200, 2013.
[14] F. Meng, X. Wang, T. Li, and Y. Chen, "Influence of cylinder liner vibration on lateral motion and tribological behaviors for piston in internal combustion engine," In: Proceedings of the Institution of Mechanical Engineers Part J-Journal of Engineering, vol. 229, no. 2, pp. 151-167, Feb. 2015.

[15] Y. Tian, and Z. M. Ripin, "Analysis of piston secondary motion," Journal of Sound and Vibration, vol. 332, no. 20, pp. 5162-5176, Sep. 2013.

[16] Z. N. Zhang, and Y. B. Xie, "Analysis of piston secondary motion considered the piston connecting rod crankshaft variable inertia effect," Journal of Shanghai Jiao Tong University, vol. 44, no. 4, pp. 554-559, Apr. 2010.

[17] Y. B. Chen, Analysis and Structural Strengthening Design of Dynamic Characteristics of Crankshaft and Piston System, Zhejiang University, Zhejiang, ON, China, 2011.

[18] P. D. McFadden, and S. R. Turnbull, "Dynamic analysis of piston secondary motion in an internal combustion engine under nonlubricated and fully flooded lubricated conditions," In: Proceedings of the Institution of Mechanical Engineers Part J-Journal of Engineering Science, vol. 225, no. 11, pp. 2575-2585, 2011.

[19] M. D. Johann, D. D. Thomas, and E. D. Holger, "Friction power measurements of a fired gasoline engine influence of installation clearance and piston pin offset," MTZ Worldwide, vol. 75, pp. 24$29,2014$.

(C) Hongwei et al.; Licensee Bentham Open.

This is an open access article licensed under the terms of the Creative Commons Attribution Non-Commercial License (http://creativecommons.org/licenses/by-nc/3.0/) which permits unrestricted, non-commercial use, distribution and reproduction in any medium, provided the work is properly cited. 